\title{
ANALYSIS OF THE ASSOCIATION OF NEUROLOGICAL MANIFESTATIONS IN SYSTEMIC LUPUS ERYTHEMATOSUS WITH CLINICAL AND LABORATORY PARAMETERS OF THE DISEASE. ABSTRACT
}

Mariana Costa Borges (Universidade do Sul de Santa Catarina, Palhoça, SC, Brasil), Ivânio Alves Pereira (Universidade do Sul de Santa Catarina, Palhoça, SC, Brasil)

\section{BACKGROUND}

To analyze the presence of neurological manifestations in Systemic Lupus Erythematosus (SLE) patients and associate the disease's diverse autoantibodies and other clinical manifestations.

\section{MATERIALS AND METHODS}

A retrospective cross - sectional observational study was carried out at the municipal polyclinic and at private clinic, with 110 individuals as sample with the diagnosis of SLE. Neurological manifestations were the clinical and laboratory variables considered.

\section{RESULTS}

Neurological manifestation was found in $28.2 \%$ of the patients. Psychiatric disorder was the most prevalent manifestation (21.8\%), followed by cerebrovascular disease (11.8\%), movement disorder (5.5\%), convulsive disorder $(2.7 \%)$, polyneuropathy $(10.9 \%)$, autonomic alteration $(5,5 \%)$ and cranial neuropathy $(9.1 \%)$. The manifestation of seizures was associated with cutaneous lesions $(4.1 \%, p=0.001)$ and thrombocytopenia $(23.1 \%, p=0.021)$. Patients with cerebrovascular disease presented hemolytic anemia $(50.0 \%, p=0.042)$ and positive tests for anti-B2GP1-IgG and anti-B2GP1-IgM $(23.8 \%, p=0.017, p$ $=0.013)$. Movement disorder was associated with hemolytic anemia (50.0\%, $p=0.012)$. An association between Raynaud's phenomenon (14.3\%, $p=0.036)$, anti-SSB / La positivity $(20.0 \%, p=0.035)$, lupus anticoagulant $(16.7 \%, p=0.004)$ and anti-B2GP1-IgG and anti-B2GP1-IgM $(23.8 \%, p=0.017, p=0.013)$ was also observed in cases of autonomic alterations. Polyneuropathy was associated with cutaneous SLE (13.3\%, $\mathrm{p}=0.038)$, lupus anticoagulant positivity $(23.3 \%, \mathrm{p}=0.019)$ and anti-B2GP1-IgM $(23.8 \%, \mathrm{p}=$ 0.013).

\section{CONCLUSION}

Neurological manifestations in patients with SLE are frequent. Its presence is associated with cutaneous lesions, Raynaud's phenomenon and antiphospholipids. 